\title{
DE LAS GEOGRAFÍAS CONSTRUCTIVISTAS A LAS NARRATIVAS DE VIDA ESPACIALES COMO METODOLOGÍAS GEOGRÁFICAS CUALITATIVAS
}

Alicia Lindón

Universidad Autónoma Metropolitana, Unidad Iztapalapa, México alicia.lindon@gmail.com

Resumo
Abstract

Key Words:

\section{INTRODUCCIÓN}

$0 \bigcirc 0$

La Geografía ha demostrado un intenso interés por reconstruir y volver a escribir una y otra vez la historia del pensamiento geográfico. En esas re-escrituras, la línea cronológica casi siempre permane ce indemne. Tan fuerte ha sido esta perspectiva que son numerosos los textos de autores reconocidos que llevan por título esta expresión, o bien alguna variante cercana. De igual forma, los planes de estudios de muchas universidades tienen cátedras y materias que llevan este tipo de denominación. Otra expresión de este interés se observa en la Comisión de Historia del Pensamiento Geográfico de la Unión Geográfica Internacional, creada en 1968 y recientemente - en 2008 - renombrada y ampliada en sus objetivos, como Comisión de Historia de la Geografía. Esta tradición por reconstruir el pensamiento geográfico también ha tenido cierta predilección por remontarse hasta tiempos antiguos. Era usual que uno de los hitos de arranque se ubicara en la antigüedad griega con la figura de Estrabon. Casi siempre esos recorridos del pensamiento geográfico acuerdan en que la Geografía es una disciplina muy antigua. Aunque 
estas reconstrucciones han marcado buena parte del siglo $\mathrm{XX}$, desde las primeras décadas, la práctica misma perdura. No ha perdido vigencia, pero empieza a renovarse.

No obstante, en las últimas tres décadas parecería que la Geografía fue abriendo otro frente de la reflexión abstracta con mayúsculas: es la discusión teórica en torno al concepto de espacio. Esta línea de pensamiento ha venido de la mano del reconocimiento explícito del espacio como el objeto de estudio de la disciplina. De allí, la insistencia reiterada en torno a la necesidad de aclarar ese concepto en sus diversas líneas posibles. Así el interés de los geógrafos ha ido transitando del reconocimiento de la "superficie terrestre" en todos y cada uno de sus rincones, al estudio del "espacio geográfico". Es necesario observar que no hay una continuidad clara entre quienes se interesaron por reconstruir el pensamiento geográfico y quienes posteriormente se involucraron en la discusión sobre el concepto y las concepciones de espacio. Más aun, en ocasiones los primeros suelen descalificar a los segundos bajo el juicio de que se trata de elucubraciones teóricas en torno al espacio. En este último punto no habría que perder que vista que para estos juicios, lo teórico es visto como algo ocioso. No obstante, y a pesar de los desacuerdos, todo parece indicar que esas discusiones teóricas son las que marcan más claramente el camino de una Geografía a la altura de los tiempos, y algunos geógrafos defensores de la Historia del Pensamiento también se han involucrado en la discusión teórica sobre el espacio.

Un detalle que podría parecer menor, pero que consideramos tiene hondas raíces, es que en esta segunda discusión se filtró en la Geografía y con fuerza creciente -afortunadamente- la palabra "teoría" (LINDÓN y HIERNAUX, 2006). De modo tal que se ha empezado a hablar de "teoría geográfica", incluso haciendo una relectura del pensamiento geográfico pero a través el cristal de los tipos de concepciones de espacio que han prevalecido.

Este proceso ha traído una profunda transformación de la Geografía. Nos atrevemos a plantear que se ha ido desencadenando una sutil refundación de la disciplina, mucho más en sintonía con las otras Ciencias Sociales y cada vez más distante de la vieja disciplina.

En este transcurso la palabra teoría se ha ido introduciendo crecientemente (aunque aun no es aceptada por muchos), sobre todo si se trata de adjetivarla como teoría geográfica, mientras que ha sido más plenamente incorporada cuando se ha tratado de teorías específicas sobre ciertos temas geográficos más o menos acotados ("teoría de la localización", la añeja "teoría del lugar central"....). Sin duda alguna, también se acepta la expresión "teoría social", porque ello no compromete el devenir de la disciplina. Sin embargo, finalmente ya se habla - con cierta aceptación en algunos contextos geográficos- de "teoría geográfica". Para algunos esto podría reducirse a una simple cuestión terminológica, en todo caso algo así como ponerse a tono con el tipo de discurso de las otras Ciencias Sociales. Sin embargo, consideramos que el tema tiene más profundidad. El reconocimiento explícito de que la Geografía opera con teorías geográficas representa la aceptación de que la producción de conocimiento geográfico resulta de ese proceso, siempre inconcluso, de confrontar el mundo observado con los constructos teóricos, para hacer inteligible ese mundo y así generar nuevo conocimiento.

En el reverso de este discurrir del pensamiento geográfico han ido emergiendo interrogantes importantes acerca de la aplicación de esas teorías y conceptos geográficos en la investigación empírica. Estos son interrogantes de orden metodológico, es decir sobre las posibles estrategias y caminos para descifrar la espacialidad en sus lógicas y sentidos, en las diferentes situaciones particulares. Aunque en última instancia la metodología de toda investigación empírica (como un camino) siempre será particular a ese proceso de indagación, es indudable que existe un nivel de reflexión compartida sobre esos caminos y acercamientos a la realidad a los que, en este trabajo, pretendemos otorgar centralidad. 
La Geografía es capaz de desarrollar una reflexión metodológica sobre la producción de conocimiento geográfico. Más aun, la Geografía tiene el compromiso de hacerlo como lo han hecho y lo siguen haciendo las disciplinas más reconocidas. Pero es innegable que la Geografía aun no ha generado un corpus de reflexión estrictamente metodológico. Una expresión insoslayable de ello está al alcance de las comprobaciones sencillas: Mientras existen infinidad de textos de revisión del pensamiento geográfico, casi no existen libros sobre metodología de la investigación geográfica. Seguramente que ello no es casual y posiblemente, se relacione con la tardía incorporación de la palabra teoría en la Geografía, y con la aun más tardía integración y puesta en movimiento de la teoría para entender el mundo. Finalmente, la metodología de la investigación no es otra cosa que eso: la puesta en movimiento en circunstancias particulares, de la teoría.

En ese sentido, tal vez quienes insisten en que la Geografía es una disciplina muy antigua, podrían preguntarse si todavía es válida esa afirmación. Desde la perspectiva de la producción de conocimiento en el sentido de las Ciencias Sociales contemporáneas, tal vez habría que empezar por reconocer que la Geografía es una disciplina bastante joven. Por ello, entre otras cuestiones, aun no ha producido suficiente reflexión de tipo metodológico, lo que termina generando vacíos considerables para la investigación empírica, más aun cuando se recuerda que el concepto de espacio geográfico se ha ampliado con dimensiones no materiales. De esta forma, en la investigación empírica, el geógrafo suele enfrentarse con dilemas como los siguientes: ¿Cómo observar y registrar lo no material de la espacialidad en cuestión? $\mathrm{O}$ ¿Desde qué punto de vista observarlo?, por mencionar algunos de los más evidentes.

Con esta perspectiva, en este trabajo la primera parte revisa muy someramente los replanteamientos en la concepción del espacio, solamente a los efectos de ubicar el tema para poder pasar a lo que es el objeto mismo del nuestro trabajo: el nivel de lo metodológico que en la Geografía actual se encuentra a veces sin bases y otras con unas bases que se tornan frágiles y quebradizas. Luego, en la segunda parte, se aborda el problema del otro (la alteridad) en el que se ha ido involucrando la Geografía Humana a partir de los replanteamiento en el concepto de espacio. En la tercera parte, se abre una ventana para echar una mirada a las metodologías cualitativas -o comprensivas- que se abren para esta Geografía Humana que replantea el concepto de espacio y se atreve a pensar el tema de la alteridad espacialmente. Por último nos centramos en lo que, a nuestro entender, es uno de los mayores desafíos metodológicos cualitativos que tiene frente a sí esta Geografía decidida a reconstruirse: las narrativas de vida de tipo espacial.

\section{LOS REPLANTEAMIENTOS EN LA CONCEPCIÓN ESPACIAL}

La reflexión y revisión acerca de las concepciones de espacio y de la espacialidad ocurridas en las últimas tres décadas, se han concretado en un lento deslizamiento desde la concepción del espacio como un producto social ${ }^{1}$, hacia concepciones como la del espacio vivido, experimentado y más recientemente, construido socialmente. La concepción del espacio como producto social ha traído consigo un énfasis en lo material, sin excluir la historicidad. Esta concepción ha privilegiado abordajes desde afuera de lo observado -esto es, desde el punto de vista de un observador externo- porque el espacio producido es reconocido como una huella, una marca o impronta que queda y puede ser reconocida por un observador externo. Cabe destacar que si bien la Geografía ha observado su objeto de estudio desde afuera muy frecuentemente, ello no fue acompañado de una reflexión sobre esa exterioridad como ocurrió con otras disciplinas, particularmente con la Antropología.

En esta concepción, el espacio ha venido a ser un objeto, una cosa o un hecho social (SANTOS, $1990^{2}$ ), aunque indudablemente ese hecho social es también un producto histórico. Esa marca o forma espacial 
muchas veces ha sido estudiada en sí misma, es decir más allá del sujeto que la modeló aun cuando se reconozca que el sujeto -los grupos sociales- le imprimió rasgos propios. En otros términos, el sujeto que hizo el espacio se desdibujó en el análisis geográfico por la preeminencia del espacio producido. En todo caso, cuando el sujeto se incluye suele ser como un atributo tangible del espacio. Esta concepción del espacio también muestra, indirectamente, las vecindades disciplinarias de la Geografía que desarrolla dicha concepción: la Historia, la Economía, cierta Sociología estructuralista y/o funcionalista...

Por su parte, desde la segunda concepción (el espacio vivido, representado, experimentado, construido socialmente y el lugar ${ }^{3}$ ), voces como la de Antoine Bailly (1989) han afirmado que la reflexión filosófica acerca del papel de lo imaginario y lo simbólico en nuestras prácticas es necesaria. Incluso, este autor ha advertido que éste es el camino para que la Geografía vuelva a encontrar la condición humana, que perdió cuando decidió seguir las pistas de la geometría, camufladas en lo locacional (BAILLY, 1989). Esta perspectiva -el espacio como experiencia o vivencia-, lleva consigo dificultades metodológicas ampliadas porque solo puede estudiarse desde la perspectiva del sujeto que lo experimenta: no es posible verlo desde afuera del sujeto. En este sentido, algunas voces fuertes de la Geografía más actual han señalado claramente esta cuestión: "La Geografía no se puede contentar con tomar en cuenta a los grupos sociales, también debe anclarse en el sujeto, el individuo, la persona, el actor" (DI MEO y BULEON, 2005:39). En estos términos resulta notorio que el espacio no puede ser reducido ni a una localización ("el dónde" en su versión más pura), ni tampoco a la obra o el producto material de una sociedad o de grupo social, producto que siempre sería observable y medible.

La concepción del espacio como experiencia (Tuan, 1977) resulta innegablemente relevante y ajustada al actual momento histórico caracterizado, para la Geografía, por la presencia del llamado "giro cultural" (DEAR, 1988; 2001), y para casi todas las otras disciplinas, por el tránsito hacia posturas más subjetivistas. No obstante, no se puede olvidar que casi toda la Geografía como disciplina, ha sido construida como un cuerpo de conocimiento desde enfoques materialistas y externos al sujeto-habitante. A este tipo de perspectivas, en otra ocasión las hemos denominado miradas "exocéntricas" (HIERNAUX y LINDÓN, 2004). Así, al replantear la concepción espacial hacia lo experiencial se estaría dando en la disciplina un deslizamiento desde visiones exocéntricas a otras "egocéntricas", que parten del punto de vista del sujeto, o al menos lo asumen como meta. Una circunstancia de este tipo -una perspectiva discordante con la tradición disciplinaria- implica un desafío de considerable magnitud porque tiene implicaciones encadenadas, particularmente en lo metodológico.

Dentro de esta segunda concepción del espacio en términos de experiencia espacial, el camino particular del "lugar como construcción social" trata de encontrar un punto medio que no deje de lado la materialidad del espacio en aras de una concepción exclusivamente idealista o subjetivista, pero que tampoco olvide todo lo no material con lo cual los sujetos le dan sentido al espacio (a las formas espaciales), considerando que construirlo socialmente precisamente implica hacerlo materialmente y también dotarlo de sentido. Esto último es lo que Claude Raffestin ha denominado la "semiotización del espacio", es decir la incorporación en el concepto de espacio de un conjunto de signos culturales que caracterizan a una sociedad y que este autor denomina "semiósfera" (RAFFESTIN, 1986). Muchos otros autores, han penetrado en distintas esferas de lo no material que acompaña a lo material (DEBARBIEUX, 1995; 1997). Un ejemplo que recientemente viene tomando creciente interés en cierta Geografía Urbana, es lo que ha dado en denominarse "Imaginarios Urbanos" (HIERNAUX, 2007).

Este tipo de visiones que buscan articular lo material y lo no material, no refiere a puntos "medios" en el sentido literal de la expresión, sino a una articulación de ambas dimensiones. Para el geógrafo, 
observar el mundo (y sus fragmentos) desde esta articulación supone colocarse en un lugar diferente al de la observación de lo material, pero tampoco desde lo exclusivamente ideal. Esta articulación no es ni la sumatoria de lo material y lo no material, ni lo intermedio entre ambos, ni es un punto medio entre la mirada desde adentro y desde afuera, ni entre la sociedad y el individuo, ni entre lo exocéntrico y lo egocéntrico El constructivismo ${ }^{4}$ geográfico es uno de esos caminos que busca la comprensión del espacio a partir de la articulación profunda entre lo material y lo no material desde la perspectiva de la experiencia espacial del sujeto (DI MÉO, 1999; DI MÉO, 2000; DI MÉO y BULÉON, 2005; LINDÓN, 2007a; LINDÓN, 2007b). Las Geografías constructivistas ${ }^{5}$ se alimentan en su sentido profundo de la filosofía contemporánea y las ciencias sociales que han planteado que al hablar -en un mundo siempre compartido con otros - creamos la realidad, porque nuestras palabras (piezas de un todo socialmente construido y compartido, como es el lenguaje) dan significados, reconocen ciertos elementos del mundo externo y omiten otros. Por eso, un mismo fenómeno, una misma realidad, puede ser construida de diferentes formas en función de distintos puntos de vista y de acuerdo a las formas de nombrarlas y más aun, de contarlas ${ }^{6}$. Estas ideas proceden de autores como Schutz (1974a; 1974b), Berger y Luckmann (1968), Bruner (1984; 1986), Gergen (1991), Varela (2006), entre otros.

Este planteamiento resulta pertinente para preguntarnos por la construcción social del espacio y los lugares. En esta perspectiva, el constructivismo geográfico no representaría una mediación en el sentido más literal de la expresión, o la búsqueda del punto medio, sino la revalorización de otras dimensiones: El punto de vista del sujeto es una mirada desde adentro, o dicho de otra forma es una mirada desde la perspectiva del sujeto que habita el lugar -ya sea un habitar circunstancial o prolongado-, que es reconstruida por el geógrafo a través de la interpretación. En cierta forma podría considerarse como una de las formas de betweenness propuestas por Entrikin (1991).

Estos deslizamientos han tenido implicaciones en cadena dentro de la disciplina. Esto ha implicado para la Geografía pensar en el problema de cómo conocer la experiencia espacial del otro. Y, en el nivel metodológico, esta conmoción está obligando a la disciplina a abrirse de lleno hacia enfoques cualitativos o interpretativos.

\section{EL PROBLEMA DEL SUJETO Y EL OTRO}

Uno de los aspectos más complejos es que para esta mirada el espacio ya no solo es algo material y en consecuencia, medible. El espacio así concebido también es la inmaterialidad asociada a lo material. Entonces el desafío se perfila en encontrar -en el contexto de cada investigación- formas para lograr la comprensión de la vivencia espacial del otro. Aunque también debemos reconocer que esas formas de comprensión de la experiencia espacial del otro, siempre serán desde nuestro lugar en el mundo, lo que implica tanto un stock de teorías y conceptos, como un acervo de sentido común que resulta de nuestras propias vivencias.

De esta forma, la Geografía Humana actual ha ido haciéndose cargo cada vez más del problema teórico y metodológico que otras disciplinas, como por ejemplo la Antropología pero también la Sociología, desde largo tiempo han asumido como propio y que puede expresarse en la conocida pregunta: ¿Cómo ponerse "en los zapatos del otro"? o, ¿Cómo interpretar las interpretaciones del otro? El hecho de que nuestra disciplina comience a pensar este tipo de preguntas representa un puente con las aproximaciones hermenéuticas, en el sentido de la interpretación del otro o más precisamente, de la interpretación de las interpretaciones del otro. Dicho de otra forma, esto nos acerca al problema teórico y metodológico de la articulación entre los constructos de primer nivel con los constructos de segundo nivel ${ }^{7}$, es decir, 
entre los conceptos científicos (especializados) y los de sentido común con los cuales los sujetos interactúan en la vida cotidiana. Posiblemente, para esta Geografía Humana abierta a la hermenéutica pero al mismo tiempo alerta al desafío de no desdibujar la espacialidad y subsumirse en la Teoría Social sin especificidad alguna, el interrogante central se podría replantear en los siguientes términos: “¿Cómo comprender e interpretar lo que el otro experimenta acerca de un lugar?, ¿Cómo comprender la vivencia del lugar del otro?".

Este tipo de preguntas también muestra que, para esta renovada Geografía Humana, el problema del "otro" no se resuelve directamente tomando y reproduciendo las enseñanzas de las otras disciplinas que tienen avances en cuanto a la alteridad o que tradicionalmente han incluido el tema del otro en sus indagaciones, o más aun, que se han conformado como disciplinas en torno a esa problemática como la Antropología, la Sociología, la Psicología.... El nuevo problema de la Geografía Humana no es tan simple como tomar y repetir lo dicho sobre la otredad, porque el interrogante geográfico ya no sólo es solamente por el otro (con los consecuentes problemas que ello trae aparejado, como el de las barreras de comunicación, la creación de la confianza, el establecimiento del rapport.....), sino más específicamente acerca del espacio vivido, representado, percibido o experimentado por el otro.

Al plantearse el problema de la producción de conocimiento en estos términos, la Geografía Humana empieza a romper con las tendencias que la llevaron a un olvido y desinterés por el acercamiento al sujeto de estudio, en el trabajo de campo, cuando paradójicamente a inicios del siglo XX los geógrafos vidalianos si por algo se caracterizaron, era por estar en el lugar estudiado. Esa minusvalía ha llevado a la Geografía a encasillar sus acercamientos empíricos al mundo a través de fuentes indirectas: tanto las estadísticas y datos agregados diversos producidos por las distintas instancias institucionales, o bien el consabido acercamiento a los documentos históricos. Ninguna de estas dos formas de acercamiento a la realidad es menos válida que otra en sí misma. Sin embargo, lo que tal vez merecería una revisión más fuerte -sobre todo por parte de quienes recurren a estos acercamientos de manera exclusiva- es si acaso estas aproximaciones han sido una forma de encubrir la dificultad del geógrafo para penetrar en la realidad de otras formas, básicamente todas aquellas formas que implican un acercamiento con los sujetos sociales, con el otro.

En las antípodas de esta frecuente minusvalía, sigue siendo un hito, y también una enseñanza, la perspectiva del trabajo de campo "experiencial" desarrollada por Graham Rowles a fines de los años setenta (ROWLES, 1978b; 1978b). Nos interesa el trabajo de este geógrafo particularmente por el desarrollo de la aproximación que denominara "conocimiento interpersonal": el camino intermedio entre el conocimiento objetivo, abstracto, distante y por lo mismo reduccionista, y por otro lado la búsqueda inacabada del conocimiento de la subjetividad espacial misma, que en estricto sentido es inaccesible porque nunca podremos ser el otro. El trabajo de campo experiencial, de sesgo claramente humanista, lleva consigo la esencia de las aproximaciones cualitativas en las Ciencias Sociales: La importancia de construir el acercamiento con el otro, de permitir la empatía, aun cuando el establecimiento de estos lazos pueda prolongar los tiempos necesarios para el trabajo de campo ${ }^{8}$. Y luego, una vez, tejidas esas bases interpersonales este tipo de acercamiento también reconoce la importancia de que el investigador asuma en su trabajo de campo la posibilidad de compartir experiencias no previstas con el sujeto de estudio, pero que forman parte del mundo cotidiano del sujeto. Este tipo de acercamientos permiten realizar hallazgos y aportes relevantes. Por ejemplo, uno de los hallazgos de este geógrafo anglosajón, Rowles, fue lo que él denominara la "fantasía geográfica" en referencia a la inclusión de lugares remotos -y en estricto sentido desconocidos- en la experiencia espacial cotidiana del sujeto ${ }^{9}$, y con los cuales el sujeto amplía su espacio de vida experiencialmente.

Revista da ANPEGE. v. 4, 2008 
Una cuestión no poco relevante que se desprende del interés geográfico por el sujeto y de los acercamientos como el trabajo de campo experiencial, es que la tan legitimada mirada geográfica del territorio a vuelo de pájaro, parece no articular con la experiencia espacial del sujeto anónimo. La experiencia espacial del habitante no se plantea sobrevolando la superficie terrestre, sino caminándola, o parado en ella. Entonces, desde las Geografías constructivistas, fenomenológicas y experienciales, la visión del espacio debería ser que puede tener un sujeto ubicado en un lugar, parado en algún sitio. Así, el geógrafo podría reconstruir la espacialidad que puede ver y sentir un sujeto desde algún lugar, y no seguir limitados a aquellas vistas que muestran la superficie terrestre captada a vuelo de pájaro, visiones aéreas desde afuera, desde arriba y ajenas al sujeto ${ }^{10}$. El habitante común no conoce esas visiones por su experiencia espacial, sino por contacto con mapas e información cartográfica. En síntesis, los replanteamientos en la concepción del espacio tienen innumerables consecuencias encadenadas, y muchas de ellas son de índole metodológica.

\section{EL DESEMBARCO GEOGRÁFICO CONTEMPORÁNEO EN LA INVESTIGACIÓN CUALITATIVA}

Este deslizamiento hacia las concepciones del espacio de tipo experiencial, vivido, construido socialmente, así como el creciente interés por el sujeto y la alteridad (BERDOULAY y ENTRIKIN, 1998; DEBARBIEUX, 1997; GUMUCHIAN et. al., 2003), ha ido introduciendo en la Geografía Humana interrogantes de corte metodológico, que no eran tan frecuentes por el pasado. Básicamente, nos referimos a las preguntas acerca de cómo producir información pertinente para abordar la espacialidad de acuerdo a esas renovadas miradas. Este tipo de interrogantes le han representado a la Geografía un acercamiento a las formas de producción de conocimiento de las otras Ciencias Sociales (CHIVALLON, 2000). Pero, además, la han puesto en sintonía con lo que esos otros campos del conocimiento vienen desarrollando bajo el techo amplio que se conoce como las aproximaciones o metodologías cualitativas ${ }^{11}$.

Las aproximaciones cualitativas desarrolladas por las otras Ciencias Sociales han mostrado que su potencial se asocia a interrogantes formulados desde la perspectiva del sujeto, de la experiencia del sujeto, así como sobre los significados que los sujetos le otorgan al mundo (STRAUSS y CORBIN, 1990; DENZIN y LINCOLN, 1994; ORTÍ, 1995). Por ello es que, para la Geografía Humana, las metodologías cualitativas constituyen una ventana para aproximarse a los significados que los sujetos le otorgan a los lugares, a las prácticas espacializadas, a los significados del hacer espacial del sujeto, a la experiencia espacial de manera integral. Y las visiones constructivistas del espacio -en el sentido más arriba esbozado- plantean que es a través de esas prácticas con sentido y esos significados sobre los espacios de vida, como los sujetos emprenden día a día la construcción social de cada lugar en los cuales se desarrolla la existencia. De modo tal que es en torno a ese núcleo fuerte, donde se produce el encuentro de las Geografías constructivistas (y todas aquellas Geografías que han replanteado el concepto de espacio desde la perspectiva de la experiencia espacial), con las Geografías interesadas en el problema de interpretar las interpretaciones del otro y también con las metodologías cualitativas replanteadas para comprender el espacio y sus significados.

Este curso sin duda alguna, le ha traído a la Geografía Humana un acercamiento con otros campos del conocimiento con los que ha tenido poca relación por el pasado, por ejemplo la Semiótica Espacial (PELLEGRINO, 2000a; 2000b; 2003), la lingüística pero también la Teoría Social más actual y de mayores aspiraciones teóricas ${ }^{12}$ (o teoría sociológica para ser más exactos), la Psicología cognitiva (BRUNER, 1984). En última instancia, para la Geografía Humana todo esto representa nuevas vecindades y empa- 
rentamientos disciplinarios, más diversificados que aquellos ya consolidados, como por ejemplo la larga relación con la historia, o luego con la economía.

No obstante, aun cuando las metodologías cualitativas tienen la capacidad para penetran en los significados del espacio, éstos no se presentan en sí mismos. Los significados del espacio solo surgen de la mano de las acciones o prácticas de los sujetos. Por ello Di Meo y Buleon (2005:29) han observado que el actor no es una persona en general sino una persona que actúa. O bien, como señalaran en su tiempo Berger y Luckmann (1968), los significados siempre son significados de algo. En otras palabras, esta Geografía Humana abierta al estudio de las tramas de significados, los indaga con relación a los lugares y a las prácticas que las personas despliegan en cada lugar. De modo tal que el significado viene a constituir como un velo no tangible (inmaterial) que une el lugar, con la práctica allí realizada y con el actor que la realiza. Por ello, es tan relevante la expresión de Di Meo y Buleon: es en la acción en donde se juegan los significados, y a ello le agregamos, y también en las formas espaciales se plasman esas acciones, aun aquellas efímeras. Por ello, la trilogía clave para descifrar en la investigación geográfica cualitativa es "formas espaciales, prácticas espaciales y significados de los lugares".

Estos últimos autores recientemente también han retomado el concepto de "actante" para enfatizar el actuar, o como dirían los fenomenólogos sociales, para destacar la importancia del ámbito del ejecutar. También se puede recordar que Nigel Thrift (1996) ha postulado una Geografía que identificó como "performativa del espacio", enfatizando no solo las prácticas del sujeto en el espacio sino también la componente corporal que las prácticas llevan consigo. También cabe recordar que desde fines de los años setenta, algunos geógrafos, como David Seamon -desde posturas humanistas- y Allan Pred -desde la tradición de la Time Geography- plantearon la cuestión de la corporeidad de las prácticas espaciales a través de la idea de "coreografías espaciales" (SEAMON, 1979; PRED, 1977).

En suma, si esta renovada Geografía penetra en los significados de los lugares, hay que tener en cuenta que éstos vienen hilvanados en el "hacer", en las prácticas. Entonces el desafío de la Geografía será aprender a "leer" esas prácticas, a pesar de todo lo banal y dado por hecho (taken for granted), lo natural, que suele rodear a la mayor parte de las prácticas cotidianas y constituye la cara más visible de las prácticas. En esta perspectiva surge una pregunta metodológica evidente: ¿Cómo captar esas acciones o prácticas espaciales? Las respuestas son varias y casi todas colocan a la Geografía en problemas, o al menos en ciertas posiciones no confortables, porque la alejan de su tradición, de su saber hacer y la enfrentan al problema de desarrollar un nuevo aprendizaje. Este nuevo saber hacer requiere de un verdadero acto fundacional: definir el punto desde el cual observar la realidad geográfica, sobre todo ante la evidencia de que el mirador externo (el de la vista a vuelo de pájaro o la vista aérea) -largamente empleado como el mirador "natural" y no cuestionado- ya no resulta pertinente para esta perspectiva.

La pregunta previa - ¿cómo captar estas prácticas con su espacialidad?- parecería que al menos, abre tres caminos posibles, siempre y cuando se trate prácticas que ocurren en la actualidad: un camino es la observación de las prácticas y su espacialidad. Otro camino metodológico consiste en dar cuenta de esas prácticas y su espacialidad a través de imágenes diversas. Y una tercera vía es acceder a las prácticas y sus espacios a través del discurso del propio sujeto que realiza esas prácticas. De estos tres caminos nos interesa detenernos de manera particular sobre el tercero: lo discursivo. Posiblemente, una justificación de este énfasis se pueda hallar en que, de los tres caminos el discurso es el más alejado de la tradición geográfica, que siempre encontrará más tendencia a recurrir a una imagen de un territorio (como una fotografía), o a la observación directa. Sin embargo, esta tradicional lejanía entre el interés geográfico y la discursividad priva al geógrafo de un acervo de sentido muy importante para comprender la experiencia espacial de los sujetos.

Revista da ANPEGE. v. 4, 2008 
También se debe subrayar que los tres caminos planteados sólo son pertinentes, al menos en la forma en que se los considera a continuación, cuando se trata de conocer prácticas cuya temporalidad es el presente. Eso no implica la inmediatez del instante presente, ni tampoco un presente vaciado del pasado. Más bien es una forma de ubicar al actor en un tiempo actual, que podríamos denominar "presente tenso" (DANIELS, 1985), tenso porque en "el ahora" el sujeto también incluye una carga del pasado a través de la memoria. Precisamente, la caracterización del presente en términos de lo tenso alude al instante actual y también al pasado que avanza sobre él. Incluso, el futuro también suele estar contenido en ese presente tenso, al menos a través de la anticipación que viene contenida en lo que persigue el sujeto con el actuar presente. Dicho de otra forma, estos tres caminos posibles para captar las prácticas -la observación, las imágenes y lo discursivo- no resolverían el caso del geógrafo interesado por prácticas espaciales de otro tiempo histórico, como podría preguntarse un geógrafo histórico. Esa es una perspectiva particular que no incluimos en nuestro análisis, no porque carezca de relevancia sino porque nos centramos en el caso del geógrafo que está frente al sujeto de estudio y puede interactuar cara a cara con él.

La ubicación en el presente casi nos obliga a aclarar que el presente tenso no mutila el fenómeno en cuestión porque el pasado se hace parte de ese presente, por la vía de la memoria y el acervo de conocimiento de que dispone el sujeto en el presente.

Desde el primero de estos caminos se puede plantear que las prácticas espaciales pueden ser observadas. Eso requiere de una Geografía Humana que realice una "observación densa" sobre la espacialidad, y no una observación ingenua o superficial. Sin lugar a dudas, este es el camino metodológico de la observación, que se puede replantear geográficamente como la "observación del hacer en el espacio", considerando que los sujetos habitantes actúan en el espacio. Esta forma de acercamiento no debería asimilarse a la tradicional descripción geográfica, fuertemente enumerativa. Aquí, más bien se está planteando el acercamiento por inmersión del geógrafo en el lugar de estudio, con los desafíos propios del acercamiento al otro, como ganarse la entrada al lugar y la confianza de los miembros del lugar. En este sentido, siempre será pertinente e ilustrativa la metáfora de Alfred Schutz sobre el forastero (1974): aquel que sin ser miembro tampoco es quien está de paso, está en el lugar, está adentro pero es de otro lugar. Por ello mismo, el forastero representa el lugar de observación privilegiado: puede ver lo que ven quienes son del lugar, pero puede formularse preguntas que los lugareños no se formulan porque naturalizan lo que allí acontece.

Un segundo camino metodológico para reconstruir esas prácticas espaciales y sus significados es el que se puede abrir recurriendo a las diversas imágenes materiales. Las imágenes podrán ser fotografías, dibujos.... Podrán ser producidas por el sujeto habitante cuando el geógrafo le propone que realice en ciertas condiciones tomas fotográficas, o bien le plantea y el sujeto acepta, la posibilidad de realizar dibujos (como los conocidos mapas cognitivos). En el caso de las fotografías las posibilidades son amplias, también es posible reconstruir prácticas a partir de fotografías ya producidas con anterioridad, como por ejemplo, fotografías antiguas, fotografías de un álbum de familia que posea el sujeto, o incluso fotografías que le presente el geógrafo al sujeto.

La elección de ciertas fotografías puede ser un disparador para relatar prácticas realizadas por el sujeto. La selección de una imagen antes que otra, precisamente se relaciona con el significado que el sujeto le otorga a los lugares que en ellas se representan y que desencadenan ciertas rememoraciones espaciales en el sujeto. En esta perspectiva, sin duda alguna, el geógrafo luego se enfrentará al desafío de la interpretación que va más allá de obtener una imagen clave. Más bien será necesario encontrar una estrategia para hacerle preguntas a esa imagen a fin de descifrar los significados que el sujeto habitante 
le atribuye a la imagen, y así, indirectamente, al espacio puesto en juego en la imagen. Este es el camino de las imágenes, lo gráfico e iconográfico como representaciones y simbolizaciones espaciales.

Las prácticas espaciales -recordemos que siempre están cargadas de significados- también suelen ser recordadas y habladas, y pueden llegar a constituir el hilo conductor del discurso del sujeto habitante. Por eso, "las entrevistas, las historias de vida y el análisis del discurso son estrategias metodológicas adecuadas a estas aproximaciones constructivistas para encontrar las lógicas de la acción" (DI MEO y BULEON, 2005: 37). Este es el camino de los relatos y el discurso en general. Este es un camino -muy poco, o nada, transitado por la Geografía tradicional- en el cual si nuestra disciplina decide penetrar, requiere abrirse al estudio del lenguaje verbal, aunque también del lenguaje gestual que acompaña al anterior. En suma, se trata de abrirse a las enseñanzas de la Lingüística, la Psicología cognitiva, la Filosofía narrativa..... Al respecto cabe recordar los aportes de Lorenza Mondada (2000; 2006), quien desde la lingüística y los actos del habla se aproxima a la Geografía Humana y al espacio, sobre todo en el caso particular de la ciudad. En suma, este es el camino de los relatos y el discurso sobre los espacios de vida y vividos.

Cuando las prácticas espaciales son narradas o relatadas por el sujeto-habitante que las ha realizado, el relato incluye una riqueza adicional a la caracterización de los acontecimientos, que siempre estarán más o menos distorsionados en relación con los hechos que le dieron origen. Esa riqueza adicional consiste en que los acontecimientos (la componente fáctica) se va articulando en la narrativa con retazos de una trama de sentido que para el sujeto tiene valor, y constituye parte de los cristales a través de los cuales ve y evalúa el mundo, y actúa en él. Entonces, si el tercer camino metodológico del discurso sobre las prácticas y su espacialidad es una apuesta legítima y de gran potencial para la investigación geográfica cualitativa, dentro de todas las formas de discursividad, las narrativas de vida constituyen uno de los núcleos de mayor riqueza, y dentro de ellas las que denominamos narrativas de vida espaciales (KAUFMANN, 1996; LINDÓN, 1999; PIÑA, 1989).

\section{EL CAMINO DE LAS NARRATIVAS COMO VENTANA A LAS PRÁCTICAS Y SU ESPACIALIDAD}

Es frecuente que todo lo que metodológicamente tiene una componente de discurso, en la jerga de la investigación sea reducido a la técnica de las entrevistas. No por usual deja de ser bastante riesgoso proceder de esta forma, porque se le otorga a lo discursivo el sentido -fantasioso- de que sólo es una técnica y además, muy sencilla por todo lo asimiladas en la cotidianidad que están las entrevistas en general. El riesgo de acercarse a lo discursivo así, es el de invisibilizar una serie de cuestiones complejas y profundas que se mueven en torno a su producción y más aun en el caso particular de las narrativas de vida espaciales. En estricto sentido, la entrevista casi siempre es el mecanismo técnico para contactar y dialogar con las personas en este acercamiento cualitativo. Pero el discurso supone una particular forma de construcción social de la realidad ${ }^{13}$, que todo geógrafo que toma este camino cualitativo debe conocer en profundidad y no invisibilizar -aunque fuera parcialmente- porque en ello se mueve la posibilidad de develar el fragmento del mundo que pretende conocer, o quedarse en la superficie de las apariencias. Más aun, dentro de todos los discursos posibles, las narrativas de vida espaciales son uno de especial complejidad.

Así, cuando una persona verbaliza una idea de contenido espacial vinculada a su vida, ello tiene una fuerte inercia para que realice a posteriori acciones encaminadas por esa idea. Por ejemplo, puede existir en un sujeto una idea poco clara o una imagen respecto a una posible migración, o un cambio residencial, pero en el momento de expresarlo verbalmente, esas palabras operan con capacidad para configurar

Revista da ANPEGE. v. 4, 2008 
acciones para concretarlo. Otras veces, la reconstrucción narrativa de un acontecimiento vivido le permite al narrador darle una forma particular a lo multiforme que vivió. Ello no solo tiene implicaciones configuradoras del recuerdo como algo anecdótico, sino también en su hacer futuro. Al narrarlo de cierta forma, lo interpreta en una perspectiva y será posible que ajuste otros ámbitos y relaciones de su vida de acuerdo a esa interpretación.

Por todo ello, en estas líneas que siguen evitamos referirnos a las narrativas en términos de entrevistas, aun cuando indudablemente requieren de la situación de entrevista. De igual forma, no nos referiremos al problema de la grabación, aunque tampoco puede quedar duda que las narrativas de vida solo pueden ser registradas como grabación (o videograbación). La decisión de no ubicar la aproximación en estas visiones técnicas deriva del interés por destacar la complejidad que supone la producción de una narrativa de vida espacial ${ }^{14}$, por parte de un sujeto que se encuentra cara a cara con otro, el investigador.

Esta forma de acercamiento a la realidad se funda en lo que Jerôme Bruner $(1984 ; 1986)$ denomina "pensamiento narrativo". Esta forma de pensamiento -muy antigua en la historia de la humanidad- consiste en contarnos a nosotros mismos, o a los otros, historias. La particularidad de reconocer que en esta vieja práctica opera un tipo de pensamiento responde a que, al contar esas historias, vamos construyendo los significados de nuestras experiencias. Así, la construcción del significado surge de la narración.

En cuanto a la forma de producción de la narrativa de vida es importante empezar por reconocer que en su construcción operan simultáneamente dos dimensiones: Una es la interaccional, y la otra son los juegos por los que la memoria se desliza entre el recuerdo y el olvido. En relación a lo interaccional, el investigador debe tener muy presente que ese discurso lo construye el sujeto, el narrador (el entrevistado), desplazándose espontáneamente (y sin ser consiente de ello) entre tres niveles de interacción, pasando del uno al otro y del otro al uno de manera natural y no buscada.

En primer lugar, interactúa con el investigador - el geógrafo cualitativo- que tiene frente a sí, y que le puede generar empatía y confianza para hablar de ciertas cuestiones y no de otras ${ }^{15}$, o podrá generarle desconfianza y antipatía. Este sistema interaccional responde al aquí y el ahora: el lugar en el cual se está durante la entrevista, y el tiempo presente en el que ocurre ese encuentro. Esta dinámica es compleja ya que requiere un pacto de confianza para iniciarse, usualmente entre desconocidos. Para que ese encuentro pueda sostenerse una vez iniciado, es necesario que el entrevistador esté dispuesto a entregarle al narrador el poder, para que construya libremente su relato seleccionando ciertas experiencias espaciales de su memoria, de acuerdo a estrategias discursivas y rememorativas propias del narrador. Según como se establezca esa dinámica, la construcción de la narrativa se verá facilitada u obstaculizada.

Un segundo nivel de interacción resulta de la recreación que hace el narrador de interacciones pasadas, las revive y así interactúa -de manera rememorativa y no presencial- con otras personas con las cuales ha compartido las experiencias de las que habla. A veces, en ese proceso, el narrador recrea diálogos que tuvo con esos otros en otros lugares y otros tiempos. Esto suele tomar la forma de burbujas en las que recrea discursivamente situaciones de interacción pasadas, verdaderos escenarios, es decir, lugares, tiempos, el sí mismo del narrador (es decir, el personaje que el narrador construye de sí16), los otros (como se representa a los alter el narrador), un conjunto de códigos implícitos en cada una de esas situaciones y algo que estaba en juego en la situación recreada.

Un tercer nivel de interacción, es el que el narrador va estableciendo consigo mismo, con su interior, con sus tensiones internas con lo que quiso hacer en un lugar y un tiempo, y no hizo, o con lo que hizo y no está convencido de haber querido hacer.... En todo ello, el narrador reconstruye su sí mismo, como quiere que lo vean, tanto el investigador que tiene frente a sí, como también cómo quiere ser visto so- 
cialmente en sentido más amplio: por ejemplo, como el personaje exitoso, como el personaje esforzado, como la víctima, como el poderoso, el oprimido, el perdedor....

En los tres niveles interaccionales, las personas se valen del espacio y la espacialidad de diferentes formas, con las que apuntalan y le dan más fuerza a lo relatado. Pero el espacio también le otorga anclaje y, a veces, credibilidad a lo vivido: Así, la referencia a un lugar puede ser una simple forma de indicar la localización de un acontecimiento. De igual forma suele ocurrir que la referencia a ciertos lugares puede constituir un recurso para reforzar un particular sí mismo, ya sea un lugar peligroso como expresión de un sí mismo en riesgo o un sí mismo arriesgado. Otras veces, la ubicación de los acontecimientos relatados en un lugar tradicional y lleno de historia puede ser una forma de fortalecer un sí mismo apegado a las tradiciones, o la incomodidad de un sí mismo vanguardista en un lugar tradicionalista. Hablar de un acontecimiento vivido y ubicarlo en un lugar prestigioso puede mostrarse como manifestación de un sí mismo exitoso o de grandes logros o de alto reconocimiento social; así como la referencia a lo vivido en un lugar pauperizado puede ser una manera de presentar el cuadro de vida de un sí mismo víctima, o un sí mismo oprimido o frágil. Solo son algunos ejemplos.

Desde la perspectiva de la investigación geográfica cualitativa, si el investigador dispara las condiciones de interacción como para que el sujeto elabore una narrativa de vida, tiene que asumir a priori que todos estos planos interaccionales que acaban de comentarse, comenzarán a moverse. Por ejemplo, es muy importante reconocer en cada instante con quien interactúa el narrador, ya que el tránsito de un nivel de interacción a otro, es algo que el narrador hace espontáneamente. Así, a veces una interpretación muy superficial tilda de contradicción algo que una interpretación más sutil, profunda y densa podría entender no como simples alteraciones de los hechos, sino como reconstrucciones diversas en función de cambios no anunciados del otro a quién va dirigida esa parte de la narrativa.

Todo lo anterior se refiere a la componente interaccional con sus tres planos o niveles. Pero además, en la narrativa también opera una segunda componente, que se mueve espontáneamente: es un proceso de la memoria por el cual, el narrador se sumerge (sin saberlo) en su memoria, en su acervo de múltiples experiencias, y comienza el complejo proceso de seleccionar unas (que en ese momento entran en la categoría de los recuerdos), dejar de lado otras (que pasan a ser olvidos, consientes o no) y comenzar a articular lo recordado, a organizarlo secuencialmente. Las experiencias que son dejadas como olvidos, o los aspectos de una experiencia rememorada que son olvidados, pueden ser así manejados por diversas razones: porque el narrador evalúa implícitamente que carecen de relevancia social, por evitar confrontaciones consigo mismo, por protección.

La organización secuencial de los acontecimientos vividos deriva de una necesidad del lenguaje. Lo vivido nunca tiene la linealidad que siempre exige la construcción del discurso. Entonces, el proceso de poner en palabras lo vivido y recordado, implica otorgarle secuencialidad a lo que no necesariamente la tuvo. Numerosas cuestiones que son contadas linealmente, suelen tener detrás una serie de vivencias que ocurrieron de manera simultánea. Pero el lenguaje no tiene la posibilidad de recrear todo lo simultáneo de esa forma. La comunicación tiene que contar primero algo y luego otra cuestión, porque el lenguaje es secuencial. Por eso sigue siendo tan pertinente la expresión de Franco Crespi: "en el caos de lo sin nombre, de pronto irrumpe el nombre" (CRESPI, 1997:25).

El tiempo, al menos el que se mide, también comparte este rasgo con el lenguaje, y lo mismo ocurre con el espacio cuando es considerado como extensión, el espacio corológicamente entendido. Así, la extensión espacial permite reconocer lugares sucesivos y organizarlos como una secuencia, así como puede ocurrir con la sucesión de las estaciones de una línea de Metro, o con las localidades emplazadas a lo largo de una carretera. Esa secuencialidad en la que puede moldearse el espacio, coincide con lo que

Revista da ANPEGE. v. 4, 2008 
se ha analizado como contigüidad. Por ello, muchas veces la simultaneidad que tuvo lo vivido y que el lenguaje obliga a linealizar para poder ser relatado, encuentra en el orden espacio-temporal la forma más natural de secuencializar: Las secuencias de lugares contiguos, así como la cronología de lo sucedido, devienen las pautas más frecuentes de linealización de aquella parte de lo vivido que entra en el circuito de la narración. Por ello, muchas veces el investigador busca que el sujeto entrevistado produzca una narrativa biográfica ( $\sin$ adjetivación), y la persona genera una narrativa biográfica espacial. No obstante es necesario aclarar, que el espacio narrado no solo es el secuencializable por la contigüidad. También las personas suelen construir extensos relatos de vida espaciales sobre un lugar en particular, es decir, sin reconstruir una línea de desplazamiento. De igual forma en ciertas narrativas espaciales suelen emerger cortes o rupturas espaciales muy fuertes, por ejemplo en las narrativas de migración internacional. Esta es otra forma de narrar el espacio, que no es ni un lugar demarcado, ni con base en la contigüidad.

Por todos estos complejos procesos de la memoria, del habla y de la interacción cara a cara, es que la experiencia espacial en sí misma es imposible de comunicar al otro. Lo que se puede comunicar es una versión interpretada de lo vivido. Esto se debe a que la experiencia al ser comunicada, hablada, puesta en palabras, es moldeada por las palabras. Siempre las palabras van a omitir aspectos que el lenguaje no logra recoger, y podrán exaltar otros. Entonces, la versión vivida no es idéntica a la contada, y no podrá serlo nunca. Pero al mismo tiempo, la única que es socialmente comunicable y construida es la versión que se pone en palabras, porque las palabras son un medio colectivo, el instrumento básico de construcción del vínculo social.

A lo anterior se debe agregar otro aspecto muy importante que se hace parte de la diferencia entre lo vivido y lo relatado: la narrativa ocurre en un tiempo posterior a la vivencia (puede ser muy distante de la vivencia o no tanto). Esa posterioridad temporal le da al sujeto una distancia temporal para interpretar lo vivido de una manera que puede no ser la misma que primó cuando ocurrió la experiencia. A veces el paso del tiempo también lleva consigo el distanciamiento espacial. Si eso también ocurre, la reinterpretación de lo vivido tiene más razones de ser: Rememorar algo tiempo después y desde un lugar diferente, permite hacerlo desde otra mirada.

Entonces, a partir de lo señalado precedentemente, en pocas palabras y con el riesgo del esquematismo, se puede decir que una narrativa de vida espacial es un relato organizado y secuencializado espacio-temporalmente de experiencias vividas por el sujeto en ciertos lugares. Es un relato en el cual el lugar -con toda su singularidad- se hace parte de la experiencia allí vivida, influye de alguna forma en la experiencia, le imprime una marca. Otras veces las narrativas de vida espaciales corresponden a experiencias vividas por el narrador en un conjunto de lugares que van articulándose entre sí por las experiencias mismas o por la biografía del narrador. Esto suele suceder con el caso de las narrativas sobre movilidad espacial, o sobre trayectorias de desplazamientos, en donde es la vida del narrador la que conecta los lugares que de otra forma podrían no tener vínculos, o los tendrían de otro tipo. Es necesario observar que la secuencialidad espacio-temporal de la narración no tiene que coincidir necesariamente con el orden y sucesión de los lugares referidos en la superficie topográfica, ni con la línea del tiempo cronológico. También se debe recordar que la secuencialidad no implica un pensamiento lineal. El sujeto se puede regresar en muchas ocasiones tanto en la secuencia temporal como en la espacial.

Ese producto social llamado narrativa de vida o biográfica de tipo espacial, está influido por todos los niveles antes mencionados. Es frecuente que el investigador reconozca el peso de los niveles referidos a las interacciones recreadas por el narrador con los otros y consigo mismo, así como la importancia de los procesos de la memoria. Sin embargo, lo que suele omitir el investigador es el peso de la propia presencia durante la construcción de la narrativa. Es necesario reconocerla, incluso nuestra propia presencia puede 
ser interpretada como una particular presencia social frente a la cual el sujeto re-elabora hoy lo vivido ayer, al igual que ocurre en otras situaciones de la vida social en la cual la persona, en el encuentro con alguien (que no lo esté entrevistando), reinterpreta lo vivido. Esa re-elaboración actual es un elemento valioso de este acercamiento cualitativo, porque así -de esa misma forma- se produce la vida social, y esa re-elaboración será la que el sujeto proyecte sobre sus acciones posteriores. Esa re-elaboración es lo que Graham Rowles denominó producción de "conocimiento interpersonal" entre el sujeto de estudio y el geógrafo inmerso en el trabajo de campo experiencial (1978a). Muchas veces, el investigador suele perder de vista esto porque la falacia de constituirse en un detective que busca los hechos tal como ocurrieron, le suele opacar lo realmente valioso que es esa reconstrucción de lo vivido cuando es pensado, puesto en ese medio social llamado lenguaje y frente a otro, que finalmente le representa una mirada social. Ninguna construcción de sentido resulta de una elaboración solitaria de un individuo que prescinde de los otros. En síntesis, si la narrativa biográfica espacial no es el recuento de los hechos tal como ocurrieron, sino de su elaboración intersubjetiva, eso es su mérito: en una situación de entrevista (que es una situación cuasi experimental de la producción social) se produce esa re-elaboración de experiencias espaciales pasadas.

En última instancia, la usual desvalorización de la narrativa por no ser una copia fiel de los hechos, solo se puede sostener bajo cierto concepto de realidad que puede llegar a asumir el investigador. Sobre todo se presenta esta desvalorización de la narrativa cuando no se supera la errónea sinonimia entre el mundo de las formas espaciales (como formas materiales) y la realidad geográfica. No obstante esas inercias, también se puede recordar que ciertas voces como la del geógrafo Michel Roux plantean que la "narratividad" (ROUX, 1999: 37) produce una reconfiguración coherente del mundo". Y en el mismo sentido, reconoce que "en el dominio de las humanidades, la realidad que se puede conocer es una realidad fenomenológica que procede de una relectura subjetiva que el individuo hace de su experiencia del espacio" (ROUX, 1999:36). La realidad accesible es el producto de un trabajo de reconstrucción y las narrativas son parte de la misma. No es una realidad deformada o distorsionada, es la construcción social del espacio a través del constante proceso de unir intersubjetivamente elementos que, más allá del sujeto y esa unidad llamada biografía, podrían resultar piezas sueltas. Por ejemplo, cuando un sujeto va por diferentes razones a dos lugares diferentes, ello se puede interpretar como un simple patrón de desplazamiento del sujeto. Sin embargo, también implica la conexión de dos micromundos que posiblemente no tenían una clara conexión anteriormente.

Conviene subrayar que sería un equívoco considerar que estos rasgos hacen de las narrativas un producto distorsionado pero útil porque dan cierta aproximación. Una consideración de ese tipo subvalora lo que se debería precisamente valorizar. En otras palabras, estos rasgos intrínsecos de toda narrativa de vida no le restan valor. Más bien, le otorgan un valor adicional por expresar algo más que la vivencia pasada. La narrativa toma la forma de lo microsocial que se está reconstruyendo en el momento presente, a partir de la re-elaboración de acontecimientos ya vividos, pero evaluados a través de toda la trama de sentido dentro de la cual la persona está inmersa en su aquí y ahora.

Finalmente, hay que tener en cuenta que una vez co-producida ${ }^{17}$ la narrativa biográfica espacial, el geógrafo aun se enfrenta al dilema de ¿cómo reconstruir las tramas de significados que vienen "debajo" de la narrativa o bien, que vienen contenidas o encapsuladas en el relato de prácticas espaciales, aparentemente banales? Este interrogante se refiere a un momento posterior a la situación de interacción, pero no por ello es menos complejo. En el momento de la interpretación el investigador se enfrenta, ya no al sujeto que narra y a la interacción cara a cara, sino al producto de esa narración, para intentar de descifrarlo, preguntándose qué se dice detrás de las palabras, o que palabras se han omitido por asumirlas 
como sobre-entendidos que acompañan mudamente a las palabras verbalizadas. ¿De qué significados se habla a través de una historia y sus personajes? En este sentido, para la Geografía una de las grandes dificultades es integrar lo no dicho junto a lo dicho. En otras palabras, no limitarnos a lo elemental que es la síntesis de lo dicho, sino preguntarnos por qué la persona dice esto, qué quiere decir para ella plantear esto. Sin lugar a dudas esta tarea es compleja, es la comprensión de la experiencia espacial del otro a la luz de los constructos teóricos. En este plano es necesario preguntarse por los sentidos fuertes que organizan una narrativa. Cuáles son los pocos sentidos en los que se condensan muchas palabras.

\section{REFLEXIONES FINALES}

Para la Geografía Humana, este camino -usualmente conocido como el de los diversos giros contemporáneos (LÉVY, 1999)- resulta fecundo. Para indicar que estamos transitando hacia una verdadera refundación de la disciplina en un sentido claramente contemporáneo y como ciencia enteramente social. Sin embargo, este camino no deja de estar sembrado de obstáculos que es necesario advertir, precisamente para superarlos. En este sentido, cabe destacar al menos tres observaciones particulares: Una de ellas es que la formación institucional en la disciplina solo excepcionalmente incluye acercamientos a cuestiones experienciales, subjetivas y cualitativas en sentido amplio. Y, como muy atinadamente señala Michel Roux, abordar nociones que no proceden de la Geografía -aun cuando puedan resultar muy fecundas para la refundación o la ampliación de los horizontes de la disciplina- se torna una tarea ardua, por el trabajo colosal de lectura que ello exige (ROUX, 1999:33).

Esta circunstancia contribuye a que muchas veces las metodologías cualitativas en Geografía Humana padezcan de reduccionismos considerables, como aquel en el cual lo cualitativo se limita a la realización de las consabidas entrevistas (aunque casi siempre de la forma menos cualitativa posible, es decir fuertemente dirigidas y estructuradas). Y como si ello no fuera un importante límite, aun hay que observar que lo usual es que luego, no se llegue a construir una estrategia analítica comprensiva sino que acaben siendo sometidas a comentarios casi de sentido común.

Otra expresión de esta ausencia de formación disciplinaria en esta perspectiva se halla en la predilección de los "nuevos geógrafos culturales" por las reflexiones "teóricas" sobre el espacio vivido y el lugar, al mismo tiempo que se olvida o deja de lado la producción de nuevo conocimiento geográfico a partir de la aplicación empírica de esas mismas reflexiones sobre el espacio y el lugar. Al respecto, podría resultar una enseñanza la observación del trabajo realizado por un geógrafo como Guy Di Méo, que por un lado ha mostrado grandes aspiraciones teóricas pero al mismo tiempo, esa teorización no ha dejado de aplicarla en diferentes comarcas y casos particulares.

Una cuestión que también se debería tener en cuenta es que la mayor parte del conocimiento geográfico en el sentido moderno de la expresión está construido con relación a lo material o, a la materialidad del espacio. Dicho de otra forma, una Geografía Humana que asuma al espacio en términos experienciales o incluso, como un producto socialmente construido (con todo lo experiencial que supone la construcción social), no debería olvidar la tradicional materialidad espacial. Pero, al mismo tiempo debería asumir el enorme desafío de estudiar lo no material que acompaña a lo material, o como diría Godelier (1989), "lo ideal y lo material", evitando que lo inmaterial venga a sustituir a lo material o que se conciban como dos realidades diferentes y separadas.

En el cruce de estos dos desafíos parece emerger con cierta claridad la tercera observación: La dificultad para estudiar lo no material, lo experiencial, requiere de los conocimientos de otras disciplinas que tienen considerables avances en ello, como cierta sociología de espíritu interaccionista y fenomenológico, la 
psicología cognitiva y social, o la antropología más sensible a lo simbólico. Sin embargo, esos avances solo nos dan algunos insumos para desarrollar nuestros propios abordajes sobre lo no material de la espacialidad. De lo contrario, el riesgo está en lograr profundas aproximaciones cualitativas sobre la experiencia y lo no material, pero perder la espacialidad en el camino. En suma, parecería que esta Geografía Humana que se atreve a este viaje, se encuentra en una compleja y riesgosa encrucijada: Perder el sujeto en pos de una nueva estructura (ahora de tipo cultural), o bien perder el espacio y la espacialidad, al tiempo que gana en la comprensión de lo inmaterial, lo cultural, lo simbólico y lo subjetivo. Seguramente, la reflexión y el reconocimiento de ambos riesgos, constituye un punto importante para avanzar en el conocimiento del espacio con su materialidad e inmaterialidad y desde la perspectiva del sujeto. En ese sentido, las palabras de Maurice Le Lannou (1976) siguen siendo una clave, a pesar del tiempo transcurrido desde su formulación: "Les géographes contre la Géographie": Solo es posible renovar la disciplina desde una autocrítica profunda y constructiva.

\section{Notas}

(1) Asimismo se puede considerar que las representaciones del espacio legitimadas (la cartografía) se fundan en la visión a vuelo de pájaro, que en última instancia es una visión del espacio desde "afuera".

(2) En este sentido, resulta inesperado que Milton Santos haya empleado - más aun, en su etapa tardía- la expresión de raigambre durkheimiana de "hecho social" para entender el espacio en una conceptualización que buscaba ser renovada. Esta apuesta resulta inesperada si se tiene en cuenta, que el concepto de hecho social constituyera el punto más débil de la teoría de Durkheim y que durante casi 100 años ha servido para descalificar el trabajo del sociólogo francés, porque en esencia esa visión del "hecho social" reducía "al carácter de cosa". Es innegable que Milton Santos se dedicó arduamente a la reflexión teórica, insistiendo en que la Geografía debe asumir retos teóricos al igual que otras disciplinas sociales. Pero al mismo tiempo, resulta inesperado que con un pensamiento tan agudo, y a fines del siglo XX, trasladara al espacio el viejo y vilipendiado concepto de "hecho social" de Durkheim.

(3) No obstante no existen acuerdos en cuanto a qué entender por espacio vivido, espacio de vida......

(4) Aunque la expresión constructivismo es reciente -muchos marcan el hito inicial en 1980- remite a una problemática del conocimiento muy antigua, como es la relación entre el objeto y el sujeto que conoce. Hay antecedentes en el mundo griego clásico, en el siglo XVII con Gianbattista Vico, en el siglo XVIII con Inmanuel Kant, a fines del XIX con William James y Friedrich Nietzche, en la primera mitad del XX con José Ortega y Gasset y Alfred Schutz, por nombrar solo algunas figuras prominentes.

(5) Una discusión que consideramos no aporta en el tema es lo correcto en esta línea de trabajo es hablar de "constructivistas" o "construccionistas". A nuestro entender esa distinción solo es formal, y se relaciona con problemas y dificultades resultantes de la traducción de vocablos que inicialmente proceden del inglés.

(6) Utilizamos la noción de "contar", ya sea alguna historia o evento, como una referencia a la narración.

(7) Esta última expresión se ancla en el discurso fenomenológico, particularmente schutziano (SCHUTZ, 1974a; 1974b; Schutz y Luckmann, 1977).

(8) En esa investigación fundacional Rowles (1978) expresaba: aprendí a reconocer el valor de varias horas de diálogo abierto y con escaso contenido espacial.

(9) La investigación pionera de Rowles fue con respecto a la experiencia espacial de personas de la tercera edad. Uno de los ejemplos más destacados que encuentra el autor sobre fantasía geográfica con la cual las personas mayores amplían su espacio de vida, es la inclusión de un reloj con la hora de Tokio como una referencia siempre presente, en el espacio de vida (en la casa), cuando la persona vive en Nueva York, a raíz de que un familiar muy cercano reside en Tokio. 
(10) Utilizamos la expresión vistas de pie en oposición a la mirada aérea o a vuelo de pájaro. En otras palabras, la mirada vertical acerca del espacio sería la de cualquier sujeto que observa el espacio circundante.

(11) Aunque es relevante el debate que se ha dado en las Ciencias Sociales en torno a la expresión metodologías cualitativas, discutiendo que sea ésta la forma más adecuada de nombrarlas y explorando otras alternativas (como metodologías interpretativas, comprensivas....), en esta ocasión tomamos la palabra sin entrar en esa discusión porque nos alejaría del foco de interés.

(12) Indudablemente en este punto estamos refiriéndonos a autores tales como Anthony Giddens (1995) y Pierre Bourdieu (1993).

(13) Esto se relaciona con lo que la etnometodología y los interaccionistas han mostrado: el lenguaje es lo que le da forma al pensamiento, hasta que no expresamos una idea con palabras no se configura. Y por ello mismo, el lenguaje no solo configura el pensamiento sino también las acciones, y es a través de éstas como construimos socialmente el espacio.

(14) Esto no implica desvalorizar la dimensión técnica de la entrevista en sí misma, ni de lo relativo a su grabación. Estos niveles técnicos también suponen una fuerte dosis de complejidad y expresión de ello es que se han realizado extensas reflexiones y producido numerosos textos.

(15) Respecto al sistema interaccional entrevistado-investigador en el contexto de un relato autobiográfico nos remitimos a Chanfrault-Duchet (1988).

(16) Nos referimos al sí mismo narrativo en el sentido interaccionista planteado por Pina (1989). También se puede considerar en la perspectiva de Gergen (1991). En esencia es el problema de cómo se construye el narrador a sí mismo frente al otro y a su memoria, considerando que los espacios de vida suelen ser parte destacada de esa construcción permanente del sí mismo (la identidad).

(17) Entre el narrador y el investigador.

\section{BIBLIOGRAFÍA}

BAILLY, Antoine. Lo imaginario espacial y la geografía: En defensa de la geografía de las representaciones. Anales de Geografía de la Universidad Complutense, núm. 9, 1989. p. 11-19.

BERDOULAY, Vincent; NICHOLAS, E. Lieu et sujet: Perspectives théoriques.Espace Géographique, núm. 2 , 1998. p. 111-121.

BERGER, Peter; THOMAS L. La construcción social de la realidad. Buenos Aires: Amorrortu Editores, 1968.

BOURDIEU, Pierre (1993), "Espacio social y poder simbólico”, Cosas Dichas, Barcelona: Gedisa, Col. El Mamífero Parlante, pp. 127-142.

BRUNER, Jerôme. Acción, pensamiento y lenguaje. Madrid: Editorial Alianza, 1984.

BRUNER, Jerôme. Realidad Mental y Mundos Posibles: Los Actos de la Imaginación que le dan Sentido a la Experiencia. Barcelona: Paidós, 1986.

CHANFRAULT-DUCHET, M.-F. Le système interactionnel du récit de vie. Sociétés, mayo, París, 1988. p. $26-31$. . Mitos y estructuras narrativas en la historia de vida: la expresión de las relaciones sociales en el medio rural. Historia y Fuente Oral, Núm. 14, julio-diciembre, Barcelona, 1995. p. 12-21.

CHIVALLON, C. D’un espace appelant forcément les sciences sociales pour le comprendre. In: Jacques Lévy; Michel Lussault (dirs.), Logiques de l'espace, Esprit des Lieux: Géographies à Cerisy, París : Belin, 2000. p. 299-318.

CRESPI, Franco. Acontecimiento y Estructura: Por una teoría del cambio social. Buenos Aires: Ediciones Nueva Visión. Revista da ANPEGE, v. 4, 1997. p. 03 - 27 
DANIELS, Stephen. Arguments for a Humanistic Geography. In: Johnston, Ron (Ed.), The future of Geography. Londres: Methuen, 1985.

DEAR, Michael. The postmodern challenge: reconstructing human geography, Transactions of the Institute of British Geographers, New Series, vol. 13, núm. 3, 1988. p. 262-274.

The Posmodern Turn. In: Claudio Minca (edit.), Posmodern Geography: Theory and Praxis. Oxford y Malden-Mass: Blackwell, 2001. p. 1-36,

DEBARBIEUX, Bernar. Le lieu, le territoire et trois figures de rhétorique. L'Espace Géographique, tome 24, núm. 2, 1995. p. 97-112.

. L'exploration des mondes intérieurs. In: Remy Knafou (Dir.). L'état de la géographie. París: Belin, 1997(a). p. 371-384.

. L'acteur et le territoire. Chronique d'un rendez-vous souvent annoncé mais toujours différé. Montagnes Méditerranéennes, Núm. 5, Mirabel : CERMOSEM, 1997(b). p. 65-66.

DENZIN, Norman y Yvonna Lincoln. Introduction: entering the field of qualitative research. In: Denzin, Norman; Yvonna Lincoln (edit). Handbooks of Qualitative Research, Sage. California, 1994. p. 1-17.

DI MÉO, Guy. Géographies tranquilles du quotidien. Une analyse de la contribution des sciences sociales et de la géographie à l'étude des pratiques spatiales. Cahiers de Géographie du Québec, Volume 43, núm. 118, avril, 1999. p. 75-93.

DI MÉO, Guy. Géographie sociale et territoires. París: Nathan, 2000. 317p.

. BULÉON, Pascal. L’espace social: Lecture géographique des sociétés, París: Armand Colin, 2005.

ENTRIKIN, John Nicholas. The Betweenness of Place: Towards A Geography of Modernity, Johns Hopkins University Press, 1991.

GERGEN, Kenneth J. El yo Saturado. Barcelona: Paidós, 1991.

GIDDENS, Anthony. La constitución de la sociedad. Bases para la teoría de la estructuración, Buenos Aires: Amorrortu Editores, 1995.

GODELIER, Maurice. Lo ideal y lo material: Pensamiento, economías, sociedades, Madrid: Taurus, 1989.

GUMUCHIAN, Hervé; GRASSET, Eric; LAJARGE, Romain; ROUX, Emmanuel. Les acteurs, ces oubliés du territoire, París : Anthropos-Economica, 2003. 186 p.

HIERNAUX, Daniel. Los Imaginarios Urbanos: De la teoría y los aterrizajes en los estudios urbanos. EURE: Revista Latinoamericana de Estudios Urbano-Regionales, Instituto de Estudios Urbanos y Territoriales, Pontificia Universidad Católica de Chile vol. XXXIII, núm. 99, agosto, 2007. p. 17-30.

. LINDÓN, Alicia. Repensar la periferia: De la voz a las visiones exo y egocéntricas. In: Adrián Guillermo Aguilar (coord.), Procesos Metropolitanos y Grandes Ciudades, Dinámicas recientes en México y otros países. Instituto de Geografía, PUEC, CRIM-UNAM, CONACYT, Miguel Angel Porrúa, 2004. p. 413-443.

KAUFMANN, Jean-Claude. L’entretien conpréhensif. París: Nathan, Col. Nathan Université, 1996.

LÉVY, Jacques. Le tournant géographique : Penser l'espace pour lire le monde. París : Belin, Colección Mappemonde, 1999.

LINDÓN, Alicia. Narrativas autobiográficas, memoria y mitos: una aproximación a la acción social. Economía, Sociedad y Territorio, núm. 6, vol.2. 1999. p. 295-312. 
LINDÓN, Alicia. Los imaginarios urbanos y el constructivismo geográfico: los hologramas espaciales. EURE: Revista Latinoamericana de Estudios Urbano-Regionales, Instituto de Estudios Urbanos y Territoriales, Pontificia Universidad Católica de Chile vol. XXXIII, núm. 99, agosto, 2007(a). p. 31-46.

El constructivismo geográfico y las aproximaciones cualitativas. Revista de Geografía Norte Grande, Pontificia Universidad Católica de Chile, núm. 37, 2007(b). p. 5-21.

HIERNAUX, Daniel. La geografía Humana: Un camino a recorrer. In: Daniel Hiernaux; Alicia Lindón (Dirs.). Tratado de Geografía Humana. Barcelona: Anthropos-UAM-I, 2006. p. 5-20.

MONDADA, Lorenza. Décrire la ville. La construction des savoirs urbains dans l'interaction et dans le texte. París: Anthropos, 2000.

MONDADA, Lorenza. Espacio y Lenguaje. In: Daniel Hiernaux; Alicia Lindón (Dirs.). Tratado de Geografía Humana. Barcelona: Anthropos-UAMI, 2006. p.433-460.

ORTÍ, Alfonso. Confrontación de modelos y niveles epistemológicos en la génesis e historia de la investigación social. In: Juan Manuel Delgado y Juan Gutiérrez, (editores). Métodos y técnicas cualitativas de investigación en ciencias sociales. Madrid: Editorial Síntesis, 1995. p. 87-99.

PELLEGRINO, Pierre. Le sens de l'espace: L’Époque et le lieu, Libro I. París: Anthropos, 2000(a). 152p.

Le sens de l'espace: La dynamique urbaine, Libro II, París: Anthropos, 2000(b). 267p

Le sens de l'espace: Les grammaires et les figures de l'étendue, Libro III, París: Anthropos, 2003. 261p.

PIÑA, Carlos. Sobre la naturaleza del discurso autobiográfico. Argumentos, UAM-X, México, 1989. p. 131-160

PRED, Allan. The choreography of existence: Comments on Hägerstrand's time-geography and its usefulness. Economic Geography, vol. 53, núm. 2, April, 1977. p. 207-221.

RAFFESTIN, Claude. Ecogenèse territoriale et territorialité. In: Franck Auriac y Roger Brunet (ed.). Espace, Jeux et Enjeux. Paris: Fayard-Fondation Diderot, 1986. p. 173-185.

ROUX, Michel. Géographie et complexité: les espaces de la nostalgie. París: L'Harmattan, Coll. Ouverture Philosophique, 1999.

ROWLES, Graham. Reflections on experiential fieldwork. In: David Ley y Marwin Samuels (Eds.), Humanistic geography: Prospects and problems, London: Croom-Helm, 1978(a). p. 173-193.

The prisoners of space? Exploring the geographical experiences of older. Boulder Colorado: Westview Press, 1978(b).

SANTOS, Milton. Por una geografía nueva, Madrid: Espasa Calpe, 1990.

SCHUTZ, Alfred. EL forastero. Ensayo de psicología social. Estudios sobre la teoría social. Buenos Aires: Amorrortu Editores, 1974. p. 95-107

SCHUTZ, Alfred. El problema de la realidad social. Buenos Aires; Amorrortu Editores, 1974(a).

SCHUTZ, Alfred (1974b), Estudios sobre la teoría social, Buenos Aires: Amorrortu Editores.

. LUCKMANN, Thomas. Las estructuras del mundo de la vida. Buenos Aires: Amorrortu Editores, 1977.

SEAMON, David. A Geography of the Lifeworld, New York: St. Martin's Press, 1979.

STRAUSS, Anselm; CORBIN, Juliet. Basics of qualitative research. Grounded theory, procedures and techniques. California: Sage, 1990. p. 17-47. 
THRIFT, Nigel. Spatial Formations. Londres: Sage, 1996.

TUAN, Yi-Fu. Space and place: The perspective of experience, Minneapolis: University of Minnesota, 1977. p. 235. VARELA, Francisco J. Conocer. Las ciencias cognitivas: Tendencias y perspectivas. Cartografía de las ideas actuales, Barcelona: Gedisa, 2006.

Recebido em abril de 2008

Aceito em agosto de 2008 